\title{
Narrativas de professoras: sentidos para o ensino de História, a docência e o currículo
}

\author{
Teachers' Narratives: Meanings for \\ Teaching History, Teaching and Curriculum
}

Artur Nogueira Santos e Costa*

\section{RESUMO}

Exploro, a partir de três entrevistas, os sentidos instituídos por professoras de História para a docência na escola pública, o ensino de História e o currículo pensados como dimensões mutuamente constitutivas. As entrevistas foram entendidas como evidências de "saberes docentes", que, em sua complexidade, mobilizam prescrições curriculares, fundamentos pedagógicos, experiências sociais, entre outros. Elas permitiram perceber profissionais conscientes dos desafios colocados para sua disciplina e seu trabalho, bem como evidenciaram as múltiplas camadas que configuram o ensino de História.

Palavras-Chave: ensino de História; narrativas orais; saberes docentes.

\begin{abstract}
Based on three interviews, I explore the meanings instituted by History teachers for teaching in public schools, the teaching of History and the curriculum - thought of as mutually constituting dimensions. The interviews were understood as evidence of "teaching knowledge", which, in its complexity, mobilizes curricular prescriptions, pedagogical foundations, social experiences, among others. They made it possible to perceive professionals aware of the challenges posed to their discipline and their work, as well as showing the multiple layers that configure History teaching.
\end{abstract}

Keywords: History teaching; oral narratives; Teaching knowledge.

Compreender as articulações entre ensino de História, currículos e escolas públicas é tarefa que mobiliza meus interesses de pesquisa há algum tempo. Em investigação recente, desenvolvida entre 2015 e 2017, para o mestrado em História, analisei a construção de currículos de História em escolas públicas de ensino fundamental, atento a um processo conformado por operações que movimentam a legislação educacional e curricular, as formas de organização próprias

* Universidade de Brasília (UnB), Brasília, DF, Brasil. artur-costa@hotmail.com 
de cada escola e, sobretudo, a dinâmica empreendida por professores/as da disciplina, a partir da relação com os/as estudantes (COSTA, 2019).

Nesse sentido, considerei uma definição defendida por Miguel Gonzáles Arroyo (2011), para quem currículos não são meros programas ou listas de conteúdo, mas traduzem escolhas, seleções e recortes nada neutros, que se relacionam, sim, com textos legais e prescritivos, embora não se reduzam a eles, já que se forjam e se reinventam nas práticas de ensino e aprendizagem construídas em sala de aula, com base em valores, atitudes, normas, metodologias e modos de lidar com cada conteúdo e com os materiais didáticos. $\mathrm{O}$ autor, enfim, pensa currículo como experiência concreta, carregada de historicidade e materializada por professores/as e estudantes nos enredos constituídos nas escolas.

Com esse entendimento, considerando que currículo, ensino de História e escola pública compõem um mesmo universo e que são mutuamente constitutivos, meu objetivo foi buscar evidências de como, na prática, a organização curricular de História é operada. Para isso, além do trabalho com a legislação curricular e com textos prescritivos, investi numa metodologia chamada "etnografia da prática escolar" (ANDRÉ, 2008), com o acompanhamento de aulas de História em turmas de ensino fundamental, bem como na realização de entrevistas com professoras de História. As entrevistas, especialmente, foram consideradas como indícios de "saberes docentes", que, com base em Ana Maria Monteiro (2007, p. 14), entendo como

as formas com que professores de História mobilizam os saberes que dominam para lidar com os saberes que ensinam, formas essas nas quais são articulados saberes disciplinares, saberes curriculares, saberes pedagógicos e saberes da experiência, numa criação própria e significativa para seus alunos.

Como recorte para este artigo, proponho discutir as narrativas elaboradas nas entrevistas, a fim de analisar os sentidos instituídos por essas professoras de História para a docência, o ensino de História e seu currículo. Na trilha de Stuart Hall (2016, p. 21-22), penso a produção de "sentidos" como um ato constitutivo da linguagem e de um "circuito cultural", "constantemente elaborado e compartilhado em cada interação pessoal e social da qual fazemos parte", e que, de certa forma, regula e organiza nossas práticas e condutas sociais. Como bem explica o autor, 
[...] nós concedemos sentidos às coisas pela maneira como as representamos - as palavras que usamos para nos referir a elas, as histórias que narramos a seu respeito, as imagens que delas criamos, as emoções que associamos a elas, as maneiras como as classificamos e conceituamos, enfim, os valores que nelas embutimos. (HALL, 2016, p. 21)

Entendo que os sentidos que se manifestam nos "saberes docentes" possuem historicidade, pois encontram fundamentos em certo "circuito cultural" que orienta e regula práticas e identidades docentes nas escolas públicas. Como historiador, interessa-me, aqui, analisar e discutir a historicidade dessa produção de sentidos, atentando para suas condições de produção, bem como para os valores, concepções, normas e práticas que a informam.

Com esse intuito, elegi para análise um conjunto de três entrevistas, realizadas em 2015, com professoras de História com experiências formativas diversas e com atuação em diferentes escolas estaduais de Uberlândia-MG. À exceção de uma, realizada nas dependências da Universidade Federal de Uberlândia, as demais entrevistas foram feitas no espaço escolar de atuação das professoras entrevistadas. Metodologicamente, elaborei um roteiro temático, pautado pelas seguintes questões: o cotidiano e as condições de trabalho do/a professor/a de História; os principais assuntos trabalhados em sala, os modo como eles são escolhidos e a relação que possuem com o currículo oficial (em Minas Gerais, chamado de Conteúdo Básico Comum - CBC, a proposta estadual) e com os materiais didáticos; e os desafios contemporâneos colocados para o ensino de História e para a escola pública. O roteiro não estava totalmente fechado e nem foi pensado para ser cumprido à risca. Ao contrário, no embalo da dinâmica estabelecida, foi ampliado por novas questões e temas que apareceram no decorrer da conversa com as entrevistadas.

Cabe apontar que, tal como qualquer outro procedimento de pesquisa em História, a realização de entrevistas é seletiva, não é neutra e não oferece um acesso ao passado tal qual ele aconteceu (PORTELLI, 1997). Portanto, mais do que fatos ou acontecimentos, a proposta é discutir posicionamentos, expectativas, angústias, intencionalidades que revelam um mundo de utopias, desejos e possibilidades em confronto. 


\section{TRABALHO DOCENTE E CURRÍCULOS EM SALA DE AULA}

É preciso ressaltar que os elementos presentes nas entrevistas são concernentes às experiências específicas de cada professora, ainda que elas sejam vivenciadas socialmente. Por isso, não podem ser tomados como universais ou como explicação direta para toda e qualquer realidade. Contudo, é possível perceber que as narrativas mobilizadas apresentam traços comuns ao terreno da docência em História, nas variadas escolas públicas brasileiras. Isso fica evidente, por exemplo, em entrevista realizada com a professora Amanda: ${ }^{1}$

ARTUR: Amanda, eu queria que você começasse falando um pouco sobre o cotidiano de trabalho, quais as atribuições, quais as atividades que envolve ser professora de história...

AMANDA: Então, Artur, eh... esse cotidiano, ele é marcado, assim, do meu ponto de vista... eh... vamos dizer... às vezes, com uma sobrecarga de trabalho. Uma sobrecarga de trabalho... Aliás, às vezes, não. Com uma sobrecarga de trabalho, mas, também, com uma recompensa, que é a lida diária com os meninos, que é você se repensar todos os dias ali naquela prática. [...] No meu caso, eu trabalho com muitas turmas, então tem que pensar muitos, diferentes planejamentos pro mesmo dia. [...] Você fica com as suas energias, assim, um tanto quanto exauridas. Mas, ao mesmo tempo, quando você consegue fazer um planejamento que envolve os meninos, que eles se identificam naquilo... eh... acho que é aquilo que o historiador prima na sua atividade; que você faz uma história viva, né. Aquilo que eles possam ter uma identificação, um prazer com aquela aula. Aí, é o contrário... é as suas forças se revigorando, pra encarar esse cotidiano [...]. [risos]

Essa foi a primeira questão que coloquei à professora Amanda, logo que iniciamos a entrevista. Ainda que dimensione o cotidiano de trabalho a partir de seu lugar social, os elementos escolhidos por ela para caracterizar sua rotina esboçam uma realidade que atravessa as experiências de parte significativa dos/as professores/as de História. A problemática da sobrecarga de trabalho, primeiro ponto levantado por ela, tem aparecido com frequência na literatura centrada em analisar o trabalho docente (CABRAL, OLIVEIRA e VIEIRA, 2013) e nos principais fóruns dedicados a refletir sobre o ensino de História na educação básica.

Amanda situa, portanto, uma jornada de trabalho que, em alguma medi- 
da, impõe limites para a efetivação do ensino de História. Ela se refere a uma rotina que envolve carga horária excessiva em sala de aula, formulação de diferentes planejamentos (em termos de anos escolares ou mesmo de turmas que requerem estratégias diversificadas), elaboração e correção de atividades, preenchimento de diários de classe, entre outros.

Por outro lado, no entender da entrevistada, a contraface dessa jornada exaustiva se expressa nos resultados obtidos junto aos/às estudantes, na construção de "uma história viva". Para a professora, ainda que com as dificuldades colocadas pela rotina de trabalho, o fato de conseguir planejar e dar vida a uma aula que faça sentido para os/as alunos/as, na qual eles/as se reconheçam como sujeitos históricos e da qual eles/as também sejam protagonistas, acaba por conferir um outro significado para a sua prática docente, na medida em que pensa essas operações como fundantes do ofício do/a historiador/a. Na contramão do que, por vezes, é recorrente, a professora não encara a docência como vocação, como um exercício missionário, e não assume uma postura de vitimização. Ao contrário, sem se furtar de fazer crítica a elementos considerados problemáticos, pensa o espaço da sala de aula como aquele da potencialidade, em que cabem reinvenções, descobertas e o prazer da construção do conhecimento.

Em sentido semelhante, a entrevista com a professora Lígia ${ }^{2}$ também dimensiona sentidos que se circunscrevem à docência em História:

ARTUR: Bom, Lígia, você pode falar um pouco sobre o seu trabalho? O que é ser professora, suas atribuições... e, em especial, o que é ser professora de história, na sua concepção?

LÍGIA: Bom... é... eu sou professora de história desde o ano de 2012. Nas escolas pelas quais eu passei, as públicas... eh... ser professora de história... significa que eu tenho, né, mais liberdade de poder trabalhar conteúdos que não estejam tão focados no vestibular, principalmente quando é ensino fundamental, né. Então, é possível, desde que a escola seja parceira, é possível desenvolver projetos, fazer atividades fora da sala de aula, menos "sala, lousa e giz"... eh... não seguir tão rigorosamente o planejamento... [...] E aí, ser professora, também, nesses espaços, independente da disciplina, é, também, você... pelo menos pra mim... é você desenvolver, com seus alunos, uma relação de proximidade, de respeito... eh... não é sempre que isso é possível, não é toda sala, não é todo aluno, né, mas, quando é possível isso, pra mim, é positivo. 
Essa foi a primeira entrevista que realizei. Ao final, pude observar que colocava as questões de modo muito direto e, às vezes, engessado. Avaliar o resultado foi importante, inclusive, para reorientar minha postura como pesquisador. Para começar, a professora situa sua experiência de trabalho na escola pública, em que é possível pensar sentidos para a docência e para o ensino de História que não estejam totalmente atrelados à preparação para o vestibular. Em outras passagens da entrevista, ela aponta que essa situação contrasta com o que vivenciou em instituições de ensino privadas, nas quais os programas são muito fechados, conteudistas e, na maioria das vezes, pensados para a preparação para o ingresso em um curso superior. Nesse caso, a maior liberdade de mobilizar saberes, assuntos e perspectivas diversas no ensino fundamental choca-se com o fato de que, na forma como organizaram-se os níveis de ensino do Brasil, o ensino médio acabou por assumir uma identidade muito tecnicista, orientada pelo vestibular como regulador de conteúdos, currículos e práticas. Embora não caiba enveredar por essa seara, há uma extensa bibliografia dedicada a problematizar a trajetória do ensino médio brasileiro, especialmente no que diz respeito às especificidades que marcam sua organização curricular (CORSO e SOARES, 2014).

A professora reivindica, nesse sentido, uma outra lógica para a escola pública, para o currículo e para o ensino de História, orientada por objetivos de promover uma formação mais ampla, com contornos de organização que ultrapassem o que ela chama de "sala, lousa e giz". É uma posição que dialoga com os debates mais recentes sobre o ensino de História, que apontam a potencialidade do trabalho crítico com espaços alternativos em que circulam narrativas históricas. Por exemplo, os museus. ${ }^{3}$ Não se trata de fetichizar ou idealizar as visitas aos museus ou a outros espaços, nem mesmo de pensá-las como estratégia automática de construção do conhecimento histórico. Tal como lembram Almeida e Vasconcellos (1997, p. 106-107), o trato com os museus, no âmbito do ensino de História, precisa se dar nos contornos de uma problemática de conhecimento, que vise percebê-lo como um espaço seletivo, que elabora uma dada narrativa sobre o passado e que exprime posições, ênfases e silenciamentos.

Como se sabe, somando-se às visitas "físicas", vários museus ao redor do mundo, nos últimos anos, criaram sites ou programas que permitem visitas online, o que, por um lado, amplia as possibilidades de que seus acervos sejam 
constituídos em objeto de investigação histórica e, por outro, coloca-nos o desafio permanente de investir na luta por melhoria das condições das escolas públicas, com ampliação das estruturas, do acesso à internet, entre outros.

Contudo, como destaca Lígia, para metodologias como essas se efetivarem, é preciso, inclusive, que seja estabelecida uma parceria com as equipes gestoras das escolas, que são capazes de viabilizar ou inviabilizar iniciativas como projetos ou trabalhos em espaços paralelos à sala de aula. Ao mencionar essa característica, a professora demostra perceber a complexidade do espaço escolar, fundado por hierarquias, conflitos, posições múltiplas e orientado por filosofias diversas, por concepções acerca do que seja a educação, o ensino e a aprendizagem, as quais incidem, diretamente, na rotina de trabalho do/a professor/a e na organização dos currículos de História.

Esses elementos, nos termos discutidos por Dominique Julia (2001, p. 11), movimentam o que se chama de "cultura escolar", como um conjunto de relações tensas, mutáveis, negociadas, atravessadas por pressões e resistências, que dão corpo às especificidades de cada escola. Lígia dá indícios, nesse caso, de sua expectativa de poder adotar outros modos de organização de seu trabalho com o ensino de História, nem sempre possíveis de serem concretizados, mas que alimentam sua maneira de pensar os desafios colocados para a disciplina e para a escola.

Ainda no intento de situar sua prática docente, Lígia considera a necessidade de se estabelecer uma relação afetuosa com os/as estudantes. Recusa, portanto, reduzir essa discussão a uma dimensão meramente técnica, mecânica, congelada, estática. Essa percepção dialoga com as premissas defendidas por Paulo Freire (1999), segundo o qual falar de escola e de ensino-aprendizagem é falar de relações afetivas entre pessoas concretas, que possuem suas formações, seus desejos, suas inserções no mundo. Nas demais entrevistas, também aparece essa preocupação, por parte das professoras, de que o ensino de História seja sempre estruturado com base numa proximidade com os/as estudantes, que torne possível ouvir suas demandas, suas reivindicações e, com isso, impregnar de sentido a prática docente.

Uma outra dimensão desse trabalho é situada na entrevista com a professora Giselda. ${ }^{4} \mathrm{O}$ trecho a seguir emergiu depois de Giselda apresentar o que considerava por ser professora de História, quando dirigi uma pergunta relacionada aos assuntos trabalhados em sala e ao modo como eles são selecionados: 
ARTUR: E em termos de conteúdos, de assuntos, que você trabalha nas suas aulas, nas diferentes turmas, o que que você acha importante trabalhar nessas aulas?

GISELDA: Uhum. Bom, eh, a gente não pode fugir do que é legislação, né. Então, assim, existem os Conteúdos Curriculares a ser trabalhados, e isso é um fato, né. Agora, dentro de cada conteúdo curricular, eu sempre tento discutir o momento histórico proposto pelo conteúdo, mas trazendo de forma sempre, um paralelo com a atualidade. [...] Então, assim, eu trabalho todos os conteúdos curriculares necessários, propostos, mesmo porque é uma coisa que foge do nosso controle. Mas, dentro desse conteúdo, você tem essa flexibilidade, de trabalhar com os alunos a parte crítica, né. Que eles conseguirem, mesmo, entender o que você tá falando, mas no contexto deles, da vivência deles. Então, essa questão da vivência, eu procuro sempre escutar os meus alunos, trabalhar um pouquinho a atualidade, na medida que é possível.

ARTUR: Entendi. Esses Conteúdos Curriculares que você tá mencionando é o $\mathrm{CBC}$ ?

GISELDA: Isso, o CBC.

ARTUR: Entendi. E é obrigatório a cumprir esses currículos ou não, Giselda, como que é isso?

GISELDA: Olha, a gente tem... Tem um planejamento anual, né. Dentro do planejamento, sim. A gente sempre coloca o conteúdo de acordo com cada ciclo ou cada série, né. A gente coloca isso no planejamento. Não existe, talvez, essa obrigatoriedade de você conseguir esse planejamento até o final do ano. Por quê? Se existe essa obrigatoriedade, eu não entendo como obrigatório. Por quê? Porque cada sala de aula, cada turma, tem o seu ritmo, né. Talvez, uma coisa que planejo em fevereiro, eu desconheço meu público ainda, qual que é a preparação dele, o quanto que eles sabem. Geralmente, eu procuro fazer uma sondagem com meus alunos no início do ano letivo, né, e por essa sondagem eu começo o meu trabalho. Nem sempre, o que eu planejei antes de conhecer as turmas é o que vai acontecer de fato, Artur. [...] Mas aí, a partir desse diagnóstico, eu encaixo meu planejamento. Tenho que admitir pra você que nem sempre dá tempo, entendeu?

Como se vê, ao ser perguntada quanto à seleção de temas/conteúdos a serem abordados em sala de aula, Giselda imediatamente remete-se à existência de um conjunto de prescrições curriculares que orientam a estruturação do ensino de História e que são, assim, presença marcante no percurso de traba- 
lho do/a professor/a. Paralelamente, a entrevistada faz questão de ressaltar o modo como ela se apropria dessas prescrições e as recria em sua prática cotidiana, o que, a meu ver, sinaliza o protagonismo docente na escolha e na efetivação de caminhos para o ensino e a aprendizagem, nos termos levantados pela pesquisadora Ana Maria Monteiro (2007).

Giselda explica que, independentemente do ano escolar, os conteúdos são mobilizados em virtude das demandas de aprendizado que circundam os/as estudantes, pensando sempre em uma dinâmica que não descola presente e passado. Nessa direção, a professora parece perceber que a disciplina não se ocupa meramente de fatos acabados e calcificados que se encontram prontos em um repositório, esperando para serem recolhidos. O sentido conferido para o ensino de História e para a organização curricular, aqui, assemelha-se ao que a professora Amanda chamou de "uma história viva", ao que acrescenta o investimento em uma "atitude crítica", como disciplina capaz de estabelecer diálogo com o lugar ocupado por aqueles/as estudantes no mundo, no presente.

Cabe destacar a postura reivindicada por Giselda quando indagada sobre a obrigatoriedade de cumprir com os "currículos prescritos", para usar uma denominação do teórico José Gimeno Sacristán (2004), que são aqueles previamente formulados e apresentados pela legislação. A resposta anterior já antecipava sua posição, mas Giselda retoma e defende o argumento de que, na prática diária, as prescrições são recriadas, adaptadas, nas arestas da "cultura escolar" (JULIA, 2001).

Ela aponta a elaboração do Planejamento Anual, que é usual em boa parte das escolas: no início do ano letivo, os/as professores/as de todas as disciplinas elaboram um documento contendo um planejamento acerca dos conteúdos a serem trabalhados em cada ano escolar, as metodologias e procedimentos avaliativos a serem adotados, os objetivos a serem perseguidos, entre outros. Na rede estadual de ensino de Minas Gerais, os/as docentes são orientados/as a observar os Conteúdos Básicos Comuns (CBC) para construírem seus planejamentos. Contudo, a dinâmica que confere vitalidade a esse planejamento é, por natureza, provisória, movediça. Nas palavras de Giselda, esse programa previamente formulado é confrontado com uma "sondagem" feita com suas turmas para apreender as condições de aprendizagem em que elas se inserem, o que a leva a redirecionar os caminhos, fazer novas escolhas, 
adaptar/excluir/incluir conteúdos. Fica evidenciado, aqui, que tanto a sua concepção quanto a sua prática apontam para um entendimento do currículo como movimento inacabado, em constante mutação, que envolve tensões e apropriações forjadas no chão da escola.

Novamente, a entrevista com a professora Amanda amplia esse debate. Falávamos sobre o que ela considera por ser professora de História e, tal como no caso de Giselda, acerca dos assuntos que são trabalhados em sala e o modo como eles são escolhidos. Amanda menciona a presença definidora do CBC na elaboração desse planejamento, e eu pergunto:

ARTUR: Amanda, e o CBC, o que que é esse material? Como que é a presença dele no trabalho do professor?

AMANDA: Então, Artur, ele é... o que eu posso dizer é que ele é muito de cima pra baixo. Ele foi pensando num outro governo, num outro momento, e tem uma abordagem muito política e, ao mesmo tempo, muito deficitária. Eu não consigo entender muito a lógica do $\mathrm{CBC}$. Cê tá falando do $\mathrm{CBC}$ mineiro, né? ARTUR: Sim.

AMANDA: Eu não consigo entender muito a lógica. Por exemplo, pra sexto ano, ele só tem uma abordagenzinha lá da questão do indígena, um pouquinho lá dos primórdios da humanidade... é só um exemplo. E outros conteúdos que ficam totalmente, assim, relegados. E eles enfatizam muito a história política, que é o que me deixa insatisfeita no currículo e nos livros didáticos [...].

ARTUR: E é obrigado a cumprir o CBC?

AMANDA: Ah, sim. Queria ter falado isso e esqueci anteriormente. Todo início de ano, eh, a primeira coisa que a supervisora fala, antes do bom dia, vamos dizer assim (risos), é: quero o seu planejamento de acordo com o CBC. [...] Então... e o que a supervisora vai reclamar do seu planejamento é se as habilidades do CBC não estiverem contidas. Mas depois não há uma fiscalização. Eu não fico muito bitolada, não. O dia que ela me pede o planejamento no molde do $\mathrm{CBC}$, eu vou lá e entrego o que ela quer... Mas eu sigo as minhas ideias. Assim, eu sou franca, eu não fico muito apegada ao $\mathrm{CBC}$, não. Principalmente o mineiro.

A argumentação de Amanda encontra muitos pontos comuns à de Giselda, especialmente ao afirmar sua leitura crítica da proposta curricular estadual, o CBC. A professora explicita seu protagonismo frente à proposta e, também, as estratégias que adota para driblar o engessamento do currículo. Assim como 
Gisela, ela menciona a elaboração de um Planejamento Anual condizente com a proposta curricular estadual, o qual é avaliado pelas supervisoras escolares. No entanto, Amanda aponta que, embora cumpra a formalidade de entregar o documento, suas aulas são orientadas pelos princípios que ela considera mais significativos para aquela turma, aquele assunto, aquele objetivo de aprendizagem em História, que ela mobiliza na interação entre demandas sociais, curriculares, pedagógicas e a sua experiência (Monteiro, 2007). A docência escapa, assim, aos modelos e fórmulas prontas, não responde a concepções meramente técnicas.

Sem ignorar os limites engendrados pelo currículo oficial/prescrito ou a pressão exercida pelas supervisoras escolares, como agentes de controle e fiscalização, a professora reforça a relativa liberdade que caracteriza o espaço da sala de aula. Aqui, a postura de Amanda lembrou-me de um desafio levantado pelo historiador Paulo Miceli, num texto cuja primeira edição é da década de 1980, mas que segue bastante atual e provocativo: "qualquer esforço de renovação do ensino de história exige prática corajosa. [...] É necessário ter coragem de superar e ignorar programas oficiais, burlar vigilâncias, criar e aceitar novos desafios e experiências" (Miceli, 1994, p. 40-41).

Ao fazer menção ao fato de que o $\mathrm{CBC}$ teria sido produzido "num outro governo", a professora expressa consciência de que currículos possuem vinculações políticas, respondem a demandas específicas localizadas no tempo e no espaço, traduzem modos de conceber a educação, a escola, o trabalho docente.

Especialmente quanto ao ensino de História, é interessante perceber a crítica feita por Amanda à abordagem historiográfica predominante no CBC. $\mathrm{Na}$ percepção da professora, os conteúdos elencados na proposta curricular estão estruturados na esteira de uma "história política tradicional", centrada nos grandes nomes, nos eventos marcantes, nas guerras, nos vultos dos heróis. ${ }^{5}$ Ela avança, dizendo que temas "complementares" são entremeados a esse modo de organização, como "a questão do indígena", sem que isso altere a estrutura historiográfica orientadora dos currículos.

A crítica formulada pela professora acompanha os movimentos operados na/pela historiografia, com os quais ela teve contato em sua formação inicial, no curso de graduação em História, e diz de uma profissional atenta às problemáticas constitutivas das referências de seu campo de trabalho, bem como aponta que a mera inserção de "novos assuntos" nos currículos, como as his- 
tórias e culturas indígenas e afro-brasileiras ou os estudos de gênero, não é suficiente para romper com um modelo excludente de pensar o ensino de História, ao qual ela se contrapõe.

Margarida Oliveira e Itamar Freitas (2012), em estudo sobre prescrições curriculares estaduais elaboradas entre 2007 e 2012, refletem sobre as abordagens historiográficas norteadoras das propostas, que são variadas e, muitas vezes, apresentam um descompasso entre o que se apresenta na introdução do documento e o que se elenca como conteúdos ou eixos temáticos para cada ano escolar. Ainda, nas palavras dos autores,

do ponto de vista das concepções de história que norteiam as propostas, podemos afirmar que a tônica, diferentemente do que imaginávamos, é a indefinição ou, pelo menos, a não explicitação desse ou daquele paradigma, corrente ou escola. Dois terços das propostas não indicam orientação. Traçam panorama da historiografia europeia do século XX, criticam a "história positivista", mas, ao contrário das propostas da década de 1980, não fundam as escolhas sobre um ou outro autor. (OLIVEIRA e FREITAS, 2012, p. 272)

Ao perceber e apontar essa característica, a professora Amanda se mostra consciente dos limites e das insuficiências de uma dada matriz historiográfica para contemplar as complexidades atinentes ao ensino de História. Por outro lado, tal como já apontado, sua prática em sala de aula não se reduz à mera execução dessa proposta. Ao contrário, ela afirma operar escolhas e desenvolver estratégias que permitem fazer da sala de aula um espaço de experimentação de ousadias, de outras histórias, do prazer do conhecimento.

Importa perceber a recorrência, nas entrevistas, da percepção dos currículos prescritos como pontos de partida a serem complementados, subvertidos, ampliados, confrontados, movimentados pelas escolhas efetuadas pelo/a professor/a em diálogo com os/as estudantes. O protagonismo docente emerge como um sentido compartilhado nessas narrativas, mobilizado como pilar do trabalho nas escolas. Contudo, como lembra Flávia Eloisa Caimi (2015, p. 116),

o professor opera nos limites de uma "mediação condicionada", pois, se nem tudo está determinado, também nem tudo é invenção. Os saberes ensinados e as 
práticas decorrentes dos processos educativos em sala de aula constituem uma mescla de tradição e de inovação.

A autora pensa o/a professor/a de História como aquele capaz de interpretar a "partitura do currículo", de conferir-lhe dinamicidade a partir de suas inserções sociais, das posições que defende, sem que isso signifique ignorar totalmente as forças e poderes que condicionam a existência da escola, do ensino de História e dos currículos. Assim, o protagonismo docente, a meu ver e em diálogo com Caimi, precisa ser pensado nessa ambiência, em que a ação e a agência se dão nos limites de pressões sociais. Dessa forma, as entrevistas dimensionam a importância dos saberes docentes para a compreensão dos processos de ensino-aprendizagem, pois revelam elementos, lógicas e escolhas que não podem ser observados considerando apenas os currículos oficiais.

\section{LUGAR SOCIAL DO ENSINO DE HISTÓRIA NAS NARRATIVAS DE PROFESSORAS}

Num outro conjunto de perguntas feitas na entrevista, procurei identificar qual seria o lugar social do ensino de História pensado por essas professoras. $\mathrm{Na}$ maioria das respostas, adotou-se um tom de crítica às experiências em curso nas escolas, por conta de seus limites, mas foi possível perceber, por parte das entrevistadas, alguns projetos de ensino de História que elas gostariam de ver contemplados.

$\mathrm{Na}$ entrevista com a professora Lígia, por exemplo, vários elementos apareceram, em sua análise, sobre o lugar do ensino de História na formação dos/ as estudantes:

ARTUR: Em relação ao ensino de história, qual é a sua concepção em relação à contribuição dele na formação do estudante? Qual é a relevância... No que que você acha que auxilia esses alunos...

LÍGIA: Eu acho que é interessante na medida que o professor consegue estabelecer uma relação passado/presente. Eu acho que se ficar preso nos fatos históricos congelados, e que muitas vezes isso acontece, né, por $\mathrm{N}$ motivos, não é... acho que não tem muita relevância pro aluno, não... eles também vem meio formatados de querer decorar datas, né... E aí, quando você passa um trabalho ou 
uma prova que você não tá cobrando uma data, eles ficam meio perdidos: "como assim, né, ela não tá me pedindo uma data?". Então, na medida que você consegue estabelecer uma relação passado/presente, eu acho que é interessante. E, o aluno, ele mesmo começa... ele consegue estabelecer alguns pontos. Então, eles também te pedem isso. Eu acho que cê acompanhou aquelas aulas de Brasil Monárquico, eles me pediram uma aula em que eu pudesse estabelecer uma relação daquelas revoltas regenciais, que eu tinha pedido em forma de trabalho, e porque que elas eram importantes de estudar hoje. E aí, eu não sei se você tava numa aula que eu falei que era pra gente pensar a questão indígena, a questão do negro...

ARTUR: Sim. Eu tava, sim.

LÍGIA: Eh... e aquilo ali, eu fiz aquilo ali por um pedido deles. Eles queriam tentar pensar porque que era importante estudar aquelas revoltas. Depois, o assunto acaba virando pra outros lados e aí, né... mas, nesse sentido, eu acho que é interessante. E a gente sabe que a maioria acha que não é mesmo. E pela própria forma que a história é ensinada nas escolas, né.

Como se vê, na perspectiva da professora, há uma condição para que o ensino de História ocupe lugar significativo na formação do/a estudante: é preciso que os conteúdos tenham alguma relação com o que se vive, no presente. Esse modo de significar o ensino de História foi historicizado por Nilton Mullet Pereira (2007), em artigo no qual analisa a maneira como a tendência de articular o conhecimento do presente aproximou-se do ensino de História, no contexto do final da Ditadura Militar e dos embates pela redemocratização da sociedade brasileira, ao longo da década de 1980, que impuseram reestruturações aos moldes pelos quais a História era ensinada.

Para o autor, a preocupação central que atravessou essa empreitada foi a de levar o/a estudante "a se inserir nas interações sociais, participar dos processos políticos, emitir opiniões sobre as questões da sua realidade social e, enfim, se tornarem cidadãos da cidade" (PEREIRA, 2007, p. 154). Não se trata, então, de defender uma perspectiva utilitarista ou de aplicabilidade técnica daquele conhecimento, mas de procurar reconhecer que o ensino de História e a discussão do passado como uma problemática em aberto são campos potenciais para fundamentar uma visão mais crítica do nosso mundo, do espaço social em que nos inserimos, das relações sociais que nos constituem e que constituímos e das que queremos/planejamos constituir. 
No entanto, um dos desafios colocados para a construção desse projeto tão aventado é, nas palavras da professora, superar uma perspectiva de ensino de História como alusão a fatos congelados no passado, discutidos a partir da mera memorização de datas. Essa concepção, ainda recorrente nas aulas de História, responde a uma tradição influenciada pelo modelo historiográfico do século XIX e pela elaboração dos códigos disciplinares de História nesse mesmo período, com o objetivo de compor “A História Nacional” baseada nos feitos dos grandes nomes (BITTENCOURT, 2018, p. 138).

Desse modo, o sentido atribuído por Lígia à disciplina situa, de um lado, sua consciência sobre as demandas que cercam o ensinar História e, de outro, a pertinência de investir, ainda, na crítica a esse modelo, apontando seus limites. Não é banal que, na fala da professora, tenha emergido essa percepção. Os estudos desenvolvidos no campo do ensino de História demonstram a força e a preponderância do formato enciclopédico, pautado pela "decoreba" e pela completa dissociação entre o presente e o passado que, ainda que com resistências e fissuras, direciona as aulas, os currículos e uma parte dos livros didáticos.

Pelo menos desde o final dos anos de 1980 (CABRINI, 1986) e, especialmente, desde a década de 1990 (NADAI, 1992, 1993), pesquisadores/as apontam a dificuldade de quebrar com essa lógica, por conta dos inúmeros fatores que ela abriga: a formulação dos materiais didáticos, a formação de professores/as, a visão da História corrente na sociedade e o que se espera dela, como disciplina curricular, entre outros. Não cabe, aqui, desdobrar todos esses temas, mas penso que é preciso que, ao discutirmos o ensino de História hoje, eles sejam considerados em sua historicidade e em sua complexidade.

A professora Amanda, ao comentar o mesmo assunto, adota um tom semelhante:

ARTUR: E o papel do ensino de história, especificamente?

AMANDA: Ai... (risos) Vital. Eu acho que ela deveria ser o carro chefe aí dessa escola como transformação, porque o papel da história... eu acho que ela, se não está, ela deveria tá articulando, né... articulando todas as demais o que se chama aí disciplinas... É a história que deveria criar um raciocínio histórico para que as pessoas não falassem tanta besteira, nem adotassem posturas que não são suas, né. [...] E não tô também colocando a escola como salvadora do mundo, não. Que também isso é muito pesado pra nossa disciplina. Eu digo que ela é 
fundamental, no momento em que ela é tão desvalorizada e tão atacada, ou que ela é só usada para a construção de uma memória, de uma história oficial, onde os outros sujeitos aí... muitos sujeitos não tem voz dentro desse processo. Então, se a gente conseguisse fazer com que as crianças interviessem para além daquilo que eu trabalho lá no sexto ano, ou todos anos depois, que eu fico insistindo, falando "oh, a história ela é feita por nós, nós somos sujeitos históricos". Que eles aprendessem a reconhecer ali sujeitos, projetos de sociedade... eh... então, é a história cumprindo o seu papel. A história precisa ser vida, não é aquele passado morto só praqueles que tem boa memória. [...] Mas também tem as nossas falhas nesse projeto aí, nem todas as abordagens, nem todas as metodologias e materiais propiciam que o aluno se defina ali. Então, é um mea-culpa aí que a gente faz.

Muitos dos pontos apresentados por Amanda são comuns aos que foram narrados por Lígia, o que pode remeter-nos às formações iniciais das duas professoras, ambas na Universidade Federal de Uberlândia, no final dos anos 2000 e início dos anos 2010, como um dos fundamentos dos saberes docentes articulados por elas: por exemplo, a crítica a um formato de História que divorcia presente e passado, a defesa do que a primeira chamou de uma "história que precisa ser vida" e o reconhecimento da necessária construção de um outro projeto de ensino de História capaz de colocar em tensão o formato criticado. Amanda, contudo, atrela o lugar do ensino de História ao lugar da própria escola pública, pensados como espaços capazes de gerar transformação social. O sentido da disciplina é complementado pela defesa de que ela deve tornar viável um raciocínio histórico orientador da vida no presente.

O posicionamento de Amanda dialoga com os enfrentamentos vivenciados nacionalmente na conjuntura em que se deu a entrevista, em 2015, quando tomou força o movimento conhecido como "Escola sem Partido"6 e suas críticas ao ensino de História. Daí sua menção a um momento de desvalorização e ataque à escola e à disciplina. A professora explicita várias camadas que significam sua atuação profissional e o modo como concebe o ensino de História: pensa a História como um conhecimento, um saber em que há espaço para narrativas, memórias e sujeitos dissidentes, e não apenas para o pretenso oficial. E, numa operação ambivalente, que conjuga a História como campo do conhecimento e como experiência de vida, enfatiza o fato de que aqueles/as estudantes são também partícipes da materialização de caminhos, no presente. 
Por isso, para ela, o papel do ensino de História assenta-se justamente na prerrogativa de proporcionar o reconhecimento e a desnaturalização dos muitos projetos de sociedade que tentam legitimar-se socialmente. Essa perspectiva de ensino de História precisa ser situada no bojo das lutas dos movimentos sociais (de mulheres, negros, indígenas, LGBTs etc.) pela inclusão de seus sujeitos e culturas nos processos de ensino-aprendizagem. Trata-se de demandas que disputaram e tensionaram os currículos de História e que, em alguma medida, informam e alimentam os saberes docentes da professora. Sem que a escola seja assumida como "a grande salvadora do mundo", em sentido idealizado, Amanda não deixa de pensá-la como uma alternativa para colocar em perspectiva outras possibilidades, projetos alternativos. A história viva, então, apresenta-se como aquela em que as situações não estão dadas, consolidadas, fatalmente fadadas a seguirem um dado curso. Ao contrário, para mencionar Foucault (2013, p. 3-5), é espaço da transformação, em que nada é irreversível, estável, contínuo. Tanto em Amanda como em Lígia, visualizo o anseio por potencializar o ensino de História, a fim de que nele caibam mais vozes, as instabilidades, o que é descontínuo, o que coloca as certezas em xeque.

Esses elementos também aparecem na narrativa da professora Giselda, numa outra parte da entrevista. Ao concluir os temas que havia elencado, sempre perguntava às entrevistadas se havia algo que elas consideravam importante de registrar e que não estava contemplado na conversa:

ARTUR: E, Giselda, tem alguma coisa que talvez eu não tenha contemplado nas perguntas que talvez você queira registrar?

GISELDA: Não, eu acho que o caminho é esse. Eu acho que nós precisamos levantar na sociedade, Artur, pessoas que realmente queiram se tornar aquilo que você se propõe a ser. [...] Pelas escolas que eu já passei, porque hoje tem dez anos que eu atuo aqui, mas o meu início de carreira profissional, eu passava por várias escolas. Então, aqui de Uberlândia, das mais de 60 escolas estuais que tem, eu devo ter passado numas 30. É, a cada seis meses, em uma. Então, percorrendo esse período, eu percebo que nem todas as pessoas estão realmente... ou não estão preparados, ainda, pra assumir esse cargo de professor, que é tão importante, ou talvez não seja essa profissão que queiram seguir. [...] Eu me considero... que quanto mais tempo que eu dou aula, mais preparada eu fico. A cada turma que eu entro, a cada aluno diferente que eu procuro, às vezes, conversar com ele, saber um pouquinho da história dele... [...] Então, assim, como profissional, eu vejo 
que nós precisamos nos preparar mais ainda, eu acho que a gente tem sempre que tá mantendo leituras, estudos, ouvindo o que as pessoas estão desenvolvendo, em todas as áreas. Eu acho que o educador, ele abrange pra você tudo. Vamos passar pela psicologia, que você precisa. Vamos ler qualquer texto, leia tudo que estão escrevendo, alguma coisa você vai aproveitar daquilo ali. [...] E instigar o aluno, ele tem que pensar. Eu sempre gosto disso, ele tem que pensar, ele tem que ser curioso, "porque que as coisas foram conduzidas dessa forma, e não de outra forma?". Eu acho que, pra mim, quando eu sinto que eles estão instigados a estudar, que quer saber do que aconteceu no passado, que esse passado tem uma influência na conduta do presente, é uma aula mais estimulante.

A fala de Giselda retoma o necessário investimento na construção de um sentido, por parte do/a estudante, para o ensino de História, de modo que esse saber permita ler o mundo com olhos mais críticos, mais desconfiado dos consensos, mais treinados para, como disse a professora Amanda, reconhecer os projetos que buscam espaço no social. Mas, para além das especificidades da História, a professora aborda situações que configuram a docência em boa parte das disciplinas: a questão da instabilidade no início de carreira, em que o/a professor/a passa por várias escolas, por vários ambientes de trabalho. Essa característica, no meu entender, indica que, no presente, é preciso articular a discussão sobre educação e sobre o lugar social do ensino de História às lutas pela valorização da carreira docente e pela profissionalização do/a professor/a. Ainda que, nas entrevistas, isso não apareça como o principal elemento, as entrevistadas não deixaram de pautar a questão da falta de investimento do poder público na educação, as estruturas precárias das escolas, os salários insuficientes que impõem uma longa jornada de trabalho, entre outros problemas.

Sua fala significa a docência como um fazer-se aberto, construído cotidianamente na experimentação de várias circunstâncias que tecem o chão da escola e da sala de aula, que exige estudo permanente. Por isso, recusa uma ideia estática de formação, em que, após concluir a licenciatura, o/a professor/a não precisaria mais repensar seu ofício, seus pressupostos, seus alinhamentos teóricos. Para Giselda, a formação abre um leque de possibilidades, constitui um suporte e fundamenta o/a profissional a exercitar seus saberes, a repensá-los, a fundá-los sob outros vieses, num processo que estará sempre em andamento, por sua própria natureza. Aproximo essa ideia àquela esboçada pelas 
professoras Ligia e Amanda ao defenderem a História como pulsação, como campo atravessado por instabilidades, como lugar da ousadia, de construir coletivamente. O lugar social do ensino de História, então, longe de apresentar-se como um dado estático, é construído e desconstruído permanentemente, e deve conter não só o mais previsível, mas também o inesperado.

\section{CONSIDERAÇÕES FINAIS}

Com base nas narrativas forjadas nas entrevistas, percebe-se que o ensino de História é um território minado por várias camadas de situações, que envolvem, mutuamente, a escola pública, as posições defendidas pelos/as professores/as, suas condições formativas, os currículos oficiais. Visualiza-se a centralidade do/a docente na operação de escolhas, na seleção de caminhos, na construção de estratégias que buscam dar vida ao ensino e à aprendizagem. As entrevistas revelam professoras conscientes dos desafios colocados para sua disciplina e seu trabalho, bem como expressam suas angústias e seus projetos.

Assim, a produção de sentidos empreendida pelas professoras acerca de seus saberes docentes informa, tal como lembrou Stuart Hall (2016), maneiras de ver o mundo, de se posicionar diante dele, de criar espaços de atuação, e nos diz da escola, das salas de aulas e do ensino de História como campos polissêmicos, complexos, e que, por isso mesmo, merecem ser objeto de pesquisas.

Por certo, como seria com qualquer outra fonte, os recortes que precisei operar por conta dos limites de um artigo não conseguem dar conta da integralidade das entrevistas, que são mais ricas e mais complexas do que os trechos aqui discutidos. De toda forma, penso que a análise dos saberes docentes expressados nas narrativas orais é um bom recurso para os/as que se interessam por compreender o ensino de História considerando o olhar de seus/suas protagonistas. Que a ousadia dessas professoras, ao afirmarem-se como sujeitos do conhecimento, inspire nossa utopia de lutar por um ensino de História voltado para a transformação, com espaço para muitas vozes.

\section{ENTREVISTAS}


Entrevista com a professora Amanda, concedida ao autor em 27 de outubro de 2015.

Entrevista com a professora Giselda, concedida ao autor em 19 de novembro de 2015. Entrevista com a professora Lígia, concedida ao autor em 02 de outubro de 2015.

\section{REFERENNCIAS}

ALMEIDA, Adriana Mortara, VASCONCELOS, Camilo de Melo. Por que visitar Museus? In: BITTENCOURT, Circe (Org.). O saber histórico em sala de aula. São Paulo: Contexto, 1997.

ANDRÉ, Marli Eliza Dalmazo Afonso de. Etnografia da prática escolar. 15. ed. Campinas: Papirus, 2008.

BITTENCOURT, Circe. Reflexões sobre o ensino de história. Estudos Avançados, São Paulo, v. 32, n. 93, p. 127-149, ago. 2018.

CABRAL NETO, Antônio; OLIVEIRA, Dalila Andrade; VIEIRA, Lívia Maria Fraga (Orgs.). Trabalho docente: desafios no cotidiano da educação básica. Campinas: Mercado das Letras, 2013.

CABRINI, Conceição et. al.. O ensino de história: revisão urgente. São Paulo: Brasiliense, 1986.

CAIMI, Flávia Eloisa. O que precisa saber um professor de história? História \& Ensino, Londrina, v. 21, p. 105-124, 2015.

CORSO, Ana Maria; SOARES, Solange Tolso. O Ensino Médio do Brasil: dos desafios históricos às Novas Diretrizes Curriculares Nacionais. In: X ANPED Sul, Seminário de Pesquisa em Educação da Região Sul - Reunião Científica Regional da ANPED, 2014, Florianópolis. X Anped Sul. Florianópolis: UDESC, 2014.

COSTA, Artur Nogueira Santos e Costa. Ensino de história na escola pública: percursos e práticas de currículos no ensino fundamental. Jundiaí: Paco Editorial, 2019.

FERREIRA, Marieta Morais. A nova "velha história": o retorno da história política. Estudos Históricos, Rio de Janeiro, vol. 5, n. 10, p. 265-271, 1992.

FOUCAULT, Michel. A arqueologia do saber. 8. ed. Rio de Janeiro: Forense Universitária, 2013.

FREIRE, Paulo. Educação como prática da liberdade. 23a. ed. Rio de Janeiro: Paz e Terra, 1999.

GONZÁLES ARROYO, Miguel. Currículo, território em disputa. 2. ed. Petrópolis: Vozes, 2011.

HALL, Stuart. Cultura e representação. Rio de Janeiro: Ed. da Puc-Rio/Apicuri, 2016. 
JULIA, Dominique. A cultura escolar como objeto histórico. Revista Brasileira de História da Educação, Campinas, n. 1, p. 9-43, 2001.

MICELI, Paulo. Por outras histórias do Brasil. In: PINSKY, Jaime (Org.). O ensino de história e a criação do fato. 6. ed. São Paulo: Contexto, 1994.

MONTEIRO, Ana Maria. Professores de História: entre saberes e práticas. Rio de Janeiro: Mauad X, 2007.

NADAI, Elza. O ensino de história no Brasil: trajetória e perspectiva. Revista Brasileira de História. São Paulo, v. 13, n. 25/26, p. 143-162, set. 1992/ago. 1993.

OLIVEIRA, Margarida; FREITAS, Itamar. Currículos de história e expectativas de aprendizagem para os anos finais do ensino fundamental no Brasil (2007-2012). História Hoje, São Paulo, v. 1, n. 1, p. 269-304, 2012.

PENNA, Fernando. O discurso reacionário de defesa de uma "escola sem partido". In: GALLEGO, Ester Solano. O ódio como política: a reinvenção das direitas no Brasil. São Paulo: Boitempo, 2018.

PEREIRA, Nilton Mullet. O ensino de história e o presente. Ágora, Santa Cruz do Sul, v. 13, p. 151-166, jan./jun. 2007.

PORTELLI, Alessandro. O que faz a história oral diferente? Projeto História, São Paulo, n. 14, p. 25-39, fev. 1997.

SACRISTÁN, José. Gimeno. O currículo: uma reflexão sobre a prática. 3. ed. Porto alegre: Artmed, 2000.

\section{NOTAS}

${ }^{1}$ Entrevista concedida ao autor em 27 de outubro de 2015. Amanda, à época com 36 anos de idade, era, desde 2012, professora efetiva de História em uma escola estadual de Uberlândia-MG. Concluiu o curso de graduação em História no ano de 2008 e, logo em seguida, ingressou no Mestrado em História, concluído no início de 2011. Naquele momento, atuava na escola nos períodos matutino e vespertino, além de exercer a função de Professora Supervisora do Programa Institucional de Bolsa de Iniciação à Docência, no subprojeto História.

${ }^{2}$ Entrevista concedida ao autor em 02 de outubro de 2015. Lígia é graduada e mestra em História. Concluiu o curso de licenciatura em 2009 e, em seguida, ingressou na pós-graduação. Depois de finalizar o Mestrado, em 2012, passou a atuar como professora de História nas diferentes redes de ensino: privada, municipal e estadual. Em 2015, tornou-se professora efetiva de História na rede estadual de ensino de Minas Gerais, em Uberlândia.

${ }^{3}$ Os museus foram escolhidos como exemplo, mas, obviamente, seria possível pensar em várias outras possibilidades: o trabalho com monumentos na cidade, com arquivos, a produção de narrativas orais, entre outros. Tal como os museus, qualquer outra atividade, den- 
tro ou fora de sala de aula, requer cuidados e procedimentos metodológicos específicos, que não são automáticos e dependem de cada situação-problema selecionada pelo/a professor/a e pelos/as estudantes.

${ }^{4}$ Entrevista concedia ao autor em 19 de novembro de 2015. Giselda, 45 anos de idade, à época, professora de História na rede estadual de ensino de MG, em Uberlândia. Graduada em História desde 1995, trabalhou em muitas escolas de Uberlândia, sendo que, nesta, atuava há 10 anos, embora, naquele momento, ainda não tivesse conseguido a efetividade.

${ }^{5}$ Marieta de Moraes Ferreira (1992, p. 266-267) entende a "história política tradicional" como aquela puramente narrativa, com uma descrição linear, centrada nos grandes nomes e eventos, com uma pretensão cientificista e neutra.

${ }^{6}$ O Movimento "Escola sem Partido", surgido em 2004, ganhou expressividade a partir de 2015. Sua proposta principal era a de modificar a LDB, a fim de retirar da educação conteúdos considerados "ideológicos". Fundamentado em premissas conservadoras, resultou, na prática, em censura, criminalização da docência e ataques constantes às Ciências Humanas. Recomendo, sobre esse tema, ver os trabalhos de Fernando Penna (2018).

Artigo recebido em 27 de março de 2020. Aprovado em 31 de maio de 2020. 